\title{
A phase II study of concurrent chemo-radiotherapy with weekly nedaplatin in advanced squamous cell carcinoma of the uterine cervix
}

\author{
Guangwen Yuan, Lingying Wü, Manni Huang, Nan Li and Jusheng An
}

\begin{abstract}
Background: To evaluate the efficacy and safety of concurrent chemo-radiotherapy with weekly nedaplatin for the treatment of advanced squamous cell carcinoma of the uterine cervix.

Methods: Patients with stage Ib2 to Illb squamous cell carcinoma of the uterine cervix were treated with concurrent radiotherapy and chemotherapy. The radiotherapy regimen included external beam radiation therapy (45-50.4Gy/25-28 fractions with central shielding after 30.6Gy) and high-dose-rate brachytherapy irradiation (35-49Gy/5-7 fractions to point A). The chemotherapy regimen was weekly intravenous infusion of nedaplatin (30 mg/m², once weekly, $180 \mathrm{mg} / \mathrm{m}^{2}$ for 6 weeks).

Results: Thirty patients were enrolled in this study from April 2010 to October 2010. The median age was 50.5 years (34-62). Three patients were at the clinical stage lla2, twenty at stage Illb and seven at stage Illb. Acute hematological toxicities included grade 3 leukopenia (8), neutropenia (5), anemia (2), grade 4 anemia (1), and grade 2 thrombocytopenia (6). Acute non-hematological toxicities included grade 2 liver disorders (1), diarrhea (2), nausea (2), and renal toxicity (1). There were not grade 3 or worse toxicities. 24 patients completed the treatment regimen and were evaluated for efficacy. 23 patients (95.8\%) had CR (complete response) and 1 (4.2\%) had PR (partial response) (100\% response rate). The median follow-up duration was 36 months (23-39), during which three patients relapsed after the treatment. The 3 -year PFS and OS rates were $87.5 \%$ and $91.7 \%$, respectively.
\end{abstract}

Conclusions: This phase II study suggested that concurrent chemo-radiotherapy with weekly nedaplatin was effective and safe for the treatment of advanced squamous cell carcinoma of the uterine cervix.

Keywords: Nedaplatin, Concurrent chemo-radiotherapy, Advanced cervical carcinoma

\section{Background}

Although uterine cervical carcinomas have been treated via surgery, radiation therapy, or a combination of the two for a long time, the treatment outcomes were poor. In the 1990s, numerous attempts were made to improve the prognosis of advanced uterine cervical carcinoma with concurrent radiation therapy and chemotherapy. In February 1999, the US National Cancer Institute (NCI) stated that five randomized controlled trials of concurrent radiotherapy and chemotherapy (especially with the use of cisplatin) demonstrated that the treatment was

\footnotetext{
* Correspondence: wulingying@csco.org.cn

Department of Gynecologic Oncology, Cancer Hospital of Peking Union Medical College and Chinese Academy of Medical Science, No 17 Panjiayuan South Street, Chaoyang District, Beijing 00021, People's Republic of China
}

effective to advanced uterine cervical carcinoma and decreased the risk of death by $30-50 \%$ [1-5]. The concurrent chemo-radiotherapy (CCRT) thus became the standard treatment of locally advanced uterine cervical carcinoma recommended by NCI and FIGO.

However, the adverse events (especially gastrointestinal events) associated with cisplatinare usually severe. The radiation therapy leads to gastrointestinal adverse reactions as well. The concurrent application of these two therapies significantly aggravates gastrointestinal adverse reactions, making it more difficult for patients to tolerate. Therefore, a drug with mild side effect is urgently needed for the concurrent chemo-radiotherapy.

Nedaplatin is an antineoplastic drug containing a platinum complex. It has better antitumor effects than cisplatin 
and less adverse reactions such as renal and gastrointestinal toxicities. A phase I clinical trial of nedaplatin showed that the drug should be administered by intravenous infusion with $100 \mathrm{mg} / \mathrm{m}^{2}$ at an interval of four weeks [6].

A phase II clinical trial using the dosage of $100 \mathrm{mg} / \mathrm{m}^{2}$ every four weeks showed a response rate of $46.3 \%$ (19/41 patients) in patients with uterine cervical carcinmoa [7], which was higher than that of cisplatin $(35.9 \%, 14 / 39$ patients). Although it demonstrated that nedaplatin had less severe nephrotoxicity than cisplatin, grade 3 or 4 myelosuppression happened in some patients (thrombocytopenia in $33.6 \%$ and leukopenia in $31.3 \%$ ). The author suggested that the use of nedaplatin requires extreme caution [7].

Nedaplatin has a higher response rate in uterine cervical carcinoma than cisplatin and causes less gastrointestinal and renal side effects, and less fluid volume is needed. Nedaplatin is expected to provide a longer survival and better quality of life than cisplatin.

Two other phase I clinical trials demonstrated that nedaplatin should be administered at a dose of 30 to $35 \mathrm{mg} / \mathrm{m}^{2}$ every week in the concurrent Chemoradiotherapy $[8,9]$. Yoshinage et al. conducted a dosefinding study and confirmed that the recommended dose was $35 \mathrm{mg} / \mathrm{m}^{2}$ every week [8]. Another phase I study of radiation therapy combined with nedaplatin showed that the optimal dose of weekly nedaplatin was $30 \mathrm{mg} / \mathrm{m}^{2}$. Nedaplatin could be given with minor adverse reactions and no delay in radiation therapy [9].

We conducted a single-centered phase II study to evaluate the tumor response rate, duration of response, survival time and adverse events of the concurrent chemo-radiotherapy with weekly nedaplatin in patients with advanced squamous cell carcinoma of the uterine cervix.

\section{Methods and materials Patients}

Patients diagnosed with advanced squamous cell carcinoma of the uterine cervix were enrolled into this study according to the following criteria (Table 1). Written informed consent was obtained from all patients prior to enrollment. The Protocol was permitted by the Ethics Committee of the Cancer Institute and Hospital of the Chinese Academy of Medical Sciences.

\section{Treatment methods \\ Radiation therapy}

External beam radiation therapy The details of the external beam radiation therapy using $6 \mathrm{MV} \mathrm{X}$-ray were described below. The fraction dose was $1.8 \mathrm{~Gy}$, five fractions per week. Totaling 30.6Gy using the entire pelvic irradiation field without central shielding was followed by totaling $14.4 \mathrm{~Gy}$ to $19.8 \mathrm{~Gy}$ using the entire

\section{Table 1 Inclusion criteria}

(i) Pathologically proven squamous cell carcinoma

(ii) Clinical FIGO stage Ib and lla2 with bulky tumor ( $>40 \mathrm{~mm}$, assessed by magnetic resonance imaging) or Clinical FIGO stage IIb, IIla, IIIb and IVa.

(iii) No para-aortic lymph node swelling ( $\geq 10 \mathrm{~mm}$ ) by abdominal computed tomography

(iv) No prior radiation therapy for abdomen

(v) Performance status (Eastern Cooperative Oncology Group): 0-2

(vi) Age: 18 to 70 years old

(vii) Adequate function of bone marrow, kidney and liver

white blood cell count $\geq 2500 \mathrm{~mm}^{3}$

neutrophil $\geq 1000 \mathrm{~mm}^{3}$

hemoglobin $\geq 8.0 \mathrm{~g} / \mathrm{dl}$

platelet count $\geq 75000 \mathrm{~mm}^{3}$

creatinine $\leq 2.0 \mathrm{mg} / \mathrm{dl}$

GOT and GPT $\leq 2$ times of the upper limit of normal at our institution

T.Bil $\leq 2$ times of the upper limit of normal at our institution)

(viii) Written informed consent

pelvic field with central shielding. Thus the total dose was $45.0 \mathrm{~Gy}$ to $50.4 \mathrm{~Gy}$.

Intracavitary brachytherapy Intracavitary brachytherapy, of which the fraction dose was 7 Gy to point A, was given once a week for a total of five to seven times. The total dose to point A was 35-49Gy.

Chemotherapy Nedaplatin $\left(30 \mathrm{mg} / \mathrm{m}^{2}\right)$ was dissolved in $500 \mathrm{ml}$ of $0.9 \%$ sodium chloride and infused intravenously over three hours. The first infusion was administered on the starting day of the external beam radiation therapy. The regimen was repeated weekly for six times.

The dosage of nedaplatin was decreased if grade 3 adverse events occurred; nedaplatin infusion was postponed if grade 4 adverse events occurred.

Response and toxicity evaluation The incidence and severity of adverse events were evaluated according to the National Cancer Institute-Common Toxicity Criteria, version 3.0 [10].

The tumor response was defined following the guideline of the Response Evaluation Criteria in Solid Tumors (RECIST version 1.0) [11]. CR was defined as the complete disappearance of all measurable lesions for one month after completion of the treatment. PR was defined as a more than $30 \%$ reduction in measurable lesions. Progressive disease (PD) was defined as a more than $20 \%$ increase in measurable lesions or the appearance on one or more new lesions. Stable disease (SD) was defined as neither sufficient lesion shrinkage for PR, 


\section{Table 2 Patient Characteristics}

\begin{tabular}{lc}
\hline Median Age, year-old (range) & 50.5 (34-62) \\
Performance status, $\mathrm{n}(\%)$ & 13 \\
0 & 17 \\
1 & 0 \\
FIGO stage & \\
Ila2 & 3 \\
Ilb & 20 \\
IIIb & 7 \\
Histology & \\
Squamous cell carcinoma & 30 \\
Not Squamous cell carcinoma & 0 \\
Grade & \\
NC* & 5 \\
1 & 1 \\
2 & 20 \\
3 & 4 \\
\hline
\end{tabular}

${ }^{*} \mathrm{NC}$ : not confirmed.

nor sufficient increase for PD. Patients were evaluated for response every four weeks by gynecological examination. In addition, radiological examinations were performed prior to the treatment and one month after completion of the treatment. The overall survival (OS) was defined as the time from the date of registration to death or the date of last contact. The progression free survival (PFS) was defined as the time from the date of registration to the date of last contact, disease progression, or death, whichever came first.

\section{Statistical design}

The primary endpoint of this study was to assess the overall response rate and the adverse events. The secondary endpoint was to assess PFS and OS. The patients for the analysis of adverse events should receive at least one week nedaplatin. Meanwhile, the patients for the analysis of OS and PFS should complete the concurrent chemo-radiotherapy. The Kaplan-Meier method was used to estimate the overall and progression free survival time.

Table 3 Hematological Toxicities $(n=30)$

\begin{tabular}{cccccc}
\hline & G0 & G1 & G2 & G3 & G4 \\
\hline Leukopenia & 1 & 6 & 15 & 8 & 0 \\
Neutropenia & 8 & 6 & 11 & 5 & 0 \\
Anemia & 18 & 7 & 2 & 2 & 1 \\
Thrombocytopenia & 15 & 8 & 7 & 0 & 0 \\
\hline
\end{tabular}

Table 4 Objective Response $(n=24)$

\begin{tabular}{cccccc}
\hline & $\mathbf{n}$ & CR (\%) & PR (\%) & SD (\%) & PD (\%) \\
\hline All stages & 24 & $23(95.8)$ & $1(4.2)$ & $0(0)$ & $0(0)$ \\
Stage Ila2 - IIb & 21 & $20(95.2)$ & $1(4.8)$ & $0(0)$ & $0(0)$ \\
Stage IIIb & 3 & $3(3 / 3)$ & $0(0)$ & $0(0)$ & $0(0)$ \\
\hline
\end{tabular}

\section{Results}

We enrolled thirty patients in this study from April 2010 to October 2010. Patient characteristics are presented in Table 2. The median age was 50.5 (ranging from 34 to 62 ). PSO was 13 and PS1 was 17. Three patients were at the clinical stage IIa2, twenty were at stage IIb and seven were at stage IIIb.

Four patients experienced grade 2 to grade 4 myelosuppression after the administration of nedaplatin for one to three weeks and the administration of nedaplatin was discontinued because these patients did not recover within two weeks. One patient experienced grade 2 renal toxicity and the administration of nedaplatin was discontinued because the patient did not recover within two weeks. One patient experienced grade 2 of leukopenia and nausea, and voluntarily withdrew from the study. The above six patients were only evaluated for toxicity, not for response. Twenty-four patients who completed the treatment regimen (24 out of $30,80 \%$ ) were evaluated for response.

Acute hematological toxicities were observed, including grade 3 leukopenia in eight patients, grade 3 neutropenia in five patients, grade 3 anemia in two patients, grade 4 anemia in one patient, and grade 2 thrombocytopenia in six patients (Table 3).

Acute non-hematological toxicities included grade 2 liver disorder in one patient, grade 2 diarrhea in two patients, grade 2 nausea in two patients, and grade 2 renal toxicity in one patient. No patient experienced grade 3 or greater acute non-hematological toxicities.

Patients who completed the treatment regimen were evaluated for response rate one month after completion of the treatment. Twenty-three patients (95.8\%) had CR and one (4.2\%) had PR (Table 4).

The median follow-up duration was 36 months (range, 23-39), during which three patients relapsed after the treatment. Two patients with complete response relapsed (one patient relapsed inside the radiation field and the other in the lung). The only patient with partial response underwent three courses of chemotherapy shortly after completion of the treatment, and relapsed in the lung twenty months after the treatment. The 3-year PFS and OS rates were $87.5 \%$ and $91.7 \%$, respectively (Figure 1, Figure 2).

The 3-year PFS rates were $100.0 \%(3 / 3), 88.9 \%$ and $66.7 \%(2 / 3)$ in patients with stage IIa, IIb and IIIb, respectively. Meanwhile, the 3-year OS rates were $100.0 \%(3 / 3), 88.9 \%$ and $100.0 \%(3 / 3)$ in patients at 


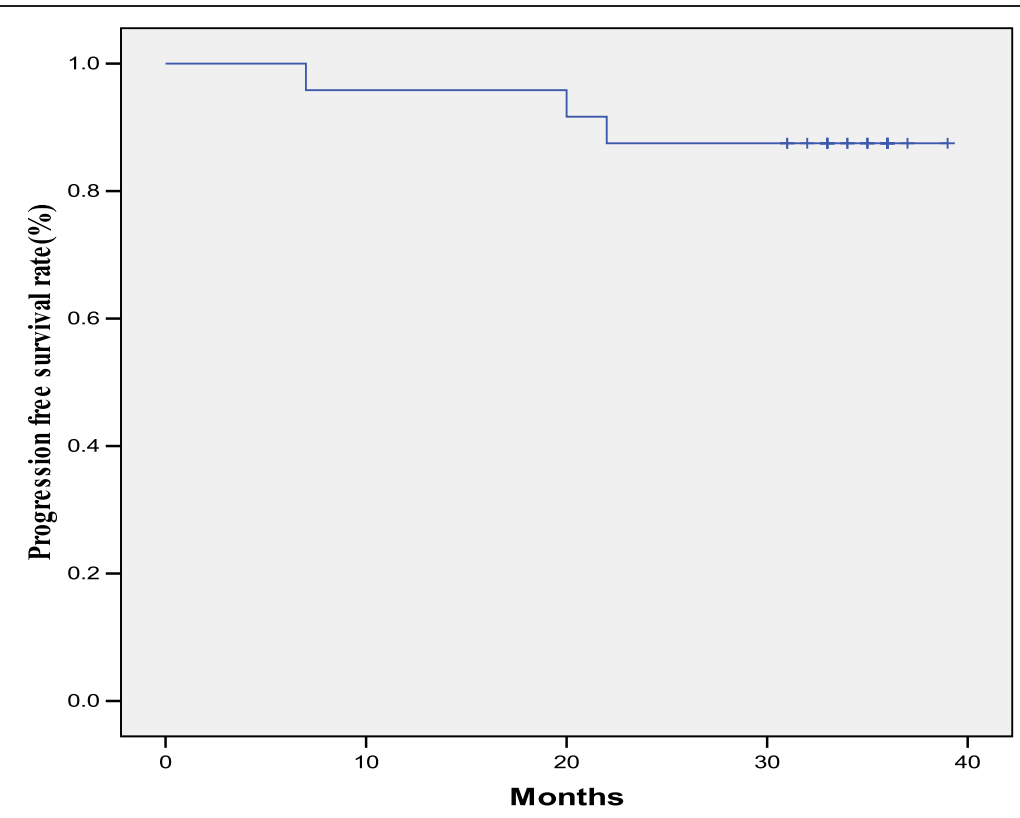

Figure 1 3-Year progression-free survival rate. The median follow-up duration was 36 months (range: 23-39).

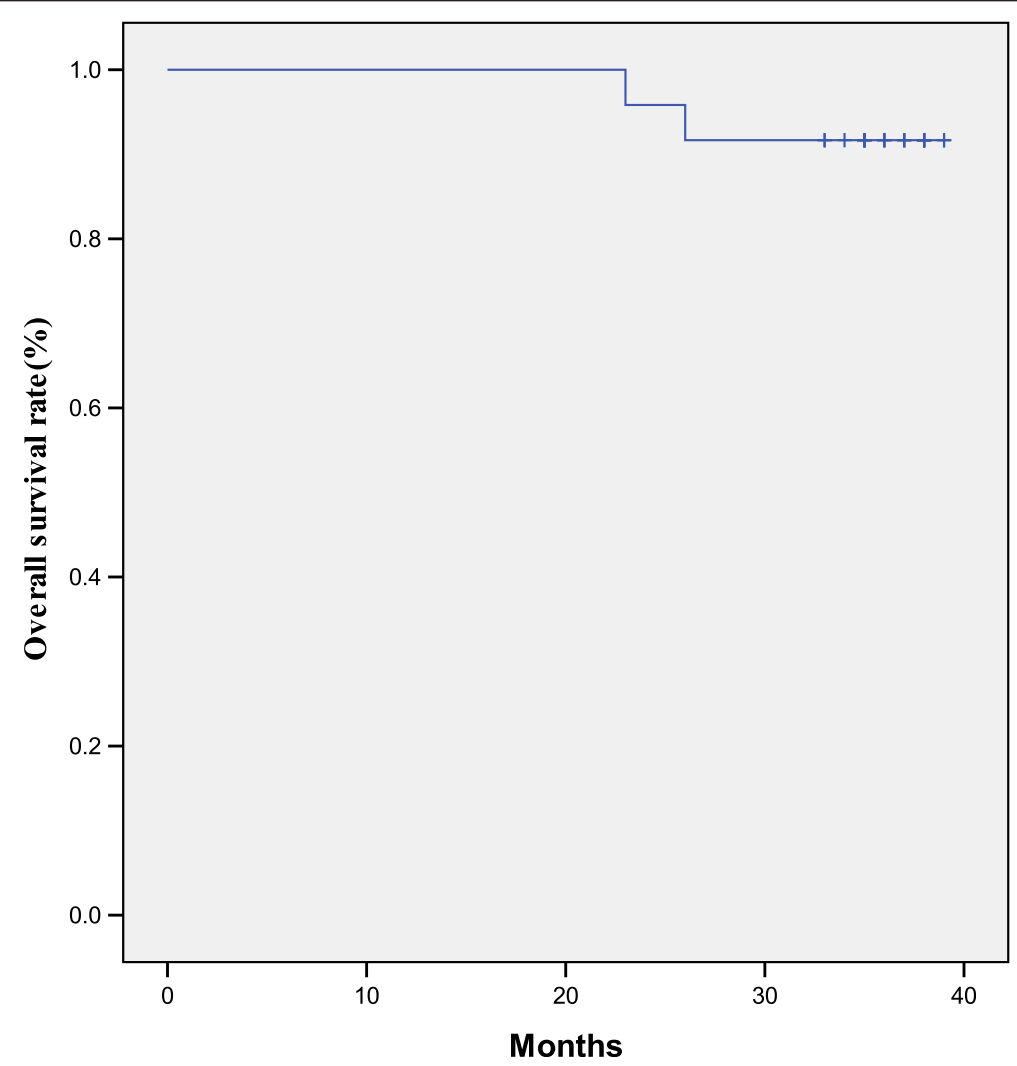

Figure 2 3-Year overall survival rate. The median follow-up duration was 36 months (range: 23-39). 
Table 5 3-Year PFS and OS Rates

\begin{tabular}{|c|c|c|c|c|c|}
\hline & No. of patients & The 3-year PFS (\%) & P-value & The 3-year OS (\%) & P-value \\
\hline All patients & 24 & 87.5 & - & 91.5 & - \\
\hline \multicolumn{6}{|l|}{ Stage } \\
\hline $11 \mathrm{a} 2$ & 3 & $3 / 3$ & & $3 / 3$ & \\
\hline $11 \mathrm{~b}$ & 18 & 88.9 & & 88.9 & \\
\hline$\| l \mid b$ & 3 & $2 / 3$ & 0.360 & $3 / 3$ & 0.710 \\
\hline
\end{tabular}

stage IIa, IIb and IIIb, respectively. These results were not significantly different (Table 5).

\section{Discussion}

The concurrent chemo-radiotherapy (CCRT) with cisplatin is currently the standard treatment for locally advanced uterine cervical carcinoma. However, the radiotherapy causes gastrointestinal adverse reactions, and cisplatin is associated with severe gastrointestinal adverse reactions. The CCRT thus inevitably aggravates gastrointestinal adverse reactions, which makes it more difficult for patients to tolerate. Cisplatin has severe renal toxicity as well. Therefore, many researchers tried to replace cisplatin with other agents as the radio-sensitizing agent in the CCRT for locally advanced uterine cervical carcinoma.

Nedaplatin (cis-diammine-glycoplatinum), a derivative of cisplatin, was developed in 1983 by Shionogi Pharmaceutical Company to provide a treatment with similar efficacy as cisplatin but less renal and gastrointestinal toxicities [12]. The preclinical evaluation of nedaplatin in cervical cancer demonstrated similar antitumor activity as cisplatin [13,14]. The incidence of nephrotoxicity was lower than that of cisplatin, due to the difference in drug distribution in the kidney. After the administration of the same dose, the amount of nedaplatin that accumulated in the rat kidney was approximately $40 \%$ of that of cisplatin, which explains why nedaplatin has less nephrotoxicity than cisplatin $[15,16]$.

The radio-sensitizing properties of nedaplatin in the setting of CCRT for advanced uterine cervical carcinoma have been evaluated in two Phase I [8,9] studies, in which weekly 30-35 mg/m $\mathrm{m}^{2}$ nedaplatin was recommended.

In a phase II study [17] of CCRT with nedaplatin for advanced uterine cervical carcinoma, the results showed that the response rate was $100 \%$ (80\% for CR $(8 / 10)$, and $20 \%$ for PR (2/10). In another phase II study [18] of CCRT with nedaplatin for advanced uterine cervical carcinoma, Yokoyama $\mathrm{Y}$ et al. reported that 40 of 45 enrolled patients completed the treatment. The response rate was $100 \%$ (90\% had CR and 10\% had PR). The median follow-up duration was 29 months (range: 8-52), the 3-year PFS and OS rates were $58.7 \%$ and $78.0 \%$ respectively. The response rate in this study was comparable to those in the two studies above. The 3-year PFS and OS rates in this study were higher than those in Yokoyama's report. The reason might be a lower proportion of patients at stage IIIb (12.5\%).
In this study, a total of 30 patients were treated with radiotherapy plus concurrent chemotherapy. The dosage of nedaplatin chosen was weekly $30 \mathrm{mg} / \mathrm{m}^{2}$. Grade 3 leukopenia, neutropenia, anemia and thrombocytopenia were found in $26.7 \%, 16.7 \%, 6.7 \%$ and $0.0 \%$ of enrolled patients, respectively. Only one patient experienced grade 4 anemia (Table 3). There was no grade 3 or 4 nonhematological toxicity. 6 (20.0\%) of the 30 enrolled patients withdrew from the trial due to myelosuppression, renal toxicity and nausea. The completion rate was $80 \%$ and the delayed duration was a maximum of 1 week. The complete response rate was $95.8 \%$ and all of the patients had a successful response. The 3-year PFS and OS rates were $87.5 \%$ and $91.5 \%$, respectively. In addition, $80 \%$ of the enrolled patients completed the study with grade 4 hematological toxicities occurred in a few patients (3.3\%), which indicated that weekly nedaplatin of $30 \mathrm{mg} / \mathrm{m}^{2}$ with concurrent radiotherapy was an effective and well-tolerated regimen for advanced uterine cervical carcinoma.

One of the limitations of this study was the small patient sample size. However, the results are sufficient to warrant further research. A randomized phase III study of this regimen were needed to validate whether nedaplatin in concurrent chemo-radiotherapy is a better choice than cisplatin with respect to the survival of patients with advanced squamous cell carcinoma of the uterine cervix.

\section{Conclusion}

This phase II study suggested that concurrent chemoradiotherapy with weekly nedaplatin was effective and safe for the treatment of advanced squamous cell carcinoma of the uterine cervix.

\section{Abbreviations}

CCRT: The concurrent chemo-radiotherapy; CR: Complete response; NCl: National Cancer Institute; OS: The overall survival; PD: Progressive disease; PFS: The progression free survival; PR: Partial response; SD: Stable disease.

\section{Competing interests}

The authors declare that they have no competing interests.

\section{Authors' contributions}

GY and LW drafted the manuscript and performed the data analysis. GY, NL and JA performed the data collection. GY, LW and MH participated in the study design and coordination. GY, LW and MH discussed the outcome during the study. All authors read and approved the final manuscript. 
Received: 16 September 2013 Accepted: 14 February 2014

Published: 18 February 2014

\section{References}

1. Peter WA III, Liu PY, Barrett RJ II, Stock RJ, Monk BJ, Berek JS, Souhami L, Grigsby P, Gordon W Jr, Alberts DS: Cisplatin and 5-fluorouracil plus radiation therapy are superior to radiation therapy as adjunctive in high-risk early stage carcinoma of the cervicx after radical hysterectomy and pelvic lymphadenectomy: report of a phase III intergroup study. J Clin Oncol 2000, 18:1606-1613.

2. Keys HM, Bundy BM, Stehman FB, Muderspach LI, Chafe WE, Suggs CL III, Walker JL, Gersell D: A comparison of weekly cisplatin during radiation therapy versus irradiation alone each followed by adjuvant hysterectomy in bulky stage IB cervical carcinoma: a randomized trial of the Gynecologic Oncology Group. N Engl J Med 1999, 340:1154-1161.

3. Whitney CW, Sause W, Bundy BN, Malfetano JH, Hannigan EV, Fowler WC Jr, Clarke-pearson DL, Liao SY: A randomized comparison of fluorouracil plus cisplatin versus hydroxyurea as an adjunct to radiation therapy in stages IIB-IVA carcinoma of the cervix with negative para-aortic lymph nodes: a Gynecologic Oncology Group and Southwest Oncology Group study. J Clin Oncol 1999, 17:1339-1348.

4. Morris M, Eifel PJ, Lu J, Grigsby PW, Levenback C, Stevens RE, Rotman M, Gershenson DM, Mutch DG: Pelvic radiation with concurrent chemotherapy versus pelvic and para-aortic radiation for high risk cervical cancer: a randomized Radiation Therapy Oncology Group clinical trial. N Engl J Med 1999, 340:1137-1143.

5. Rose PG, Bundy BN, Watkins EB, Thigpen JT, Deppe G, Maiman MA, Clarke-Pearson DL, Insalaco S: Concurrent cisplatin-based chemoradiation improves progression free and overall survival in advanced cervical cancer: results of a randomized Gynecologic Oncology Group study. N Engl J Med 1999, 340:1144-1153.

6. Ota K, Wakui A, Majima H, Niitani H, Inuyama Y, Ogawa M, Ariyoshi Y, Yoshida O, Taguchi T, Kimura I: Phase I study of a new platinum complex 254-S, cis-diammine (glycolato)-platinum (II). Gan To Kagaku Ryoho 1992, 19:855-861.

7. Kato T, Nishimura H, Yakushiji M, Noda K, Terashima Y, Takeuchi S, Takamizawa H, Suzuki M, Arai M, Ota M: Phase II study of 254-S (cis-diammine glycolato-platinum) for gynecological cancer. Gan To Kagaku Ryoho 1992, 19:695-701.

8. Yoshinaga K, Niikura H, Ogawa Y, Nemoto K, Nagase S, Takano T, Ito K, Yaegashi N: Phase I trial of concurrent chemoradiation with weekly nedaplatin in patients with squamous cell carcinoma of the uterine cervix. Gynecol Oncol 2007, 104:36-40.

9. Kodama J, Takemoto M, Seki N, Nakamura K, Hongo A, Kanazawa S, Hiramatsu Y: Phase I study of weekly nedaplatin and concurrent pelvic radiotherapy as adjuvant therapy after radical surgery for cervical cancer. Int J Gynecol Cancer 2008, 18(5):1037-1041.

10. National Cancer Institute: Common Terinology Criteria for Adverse Events v3.0. http://ctep.cancer.gov/protocolDevelopment/electronic_applications/ctc.htm.

11. Therasse P, Arbuck SG, Eisenhauer EA, Wanders J, Kaplan RS, Rubinstein L, Verweij J, Glabbeke MV, Oosterom ATV, Christian MC, Gwyther SG: new guideline to evaluate the response to treatment in solid tumos. European Organization for Research and Treatment of Cancer, National Cancer Institute of the United States, National Cancer Institute of Canada. J Natl Cancer Inst 2000, 92:205-216.

12. Kanzawa F, Matsushima Y, Nakano H, Nakagawa K, Takahashi H, Sasaki Y, Saijo N: Antitumor activity of a new platinum compound (glycolate-o, o') diammineplatinum (II) (254-S), against non-small cell lung carcinoma grown in a human tumor clonogenic assay system. Anticancer Res 1988, 8:323-327.

13. Monk BJ, Alberts DS, Burger RA, Fanta PT, Hallum AV III, Hatch KD, Salmon SE: In vitro phase II comparison of the cytotoxicity of a novel platinum analog, nedaplatin (254-S), with that of cisplatin and carboplatin against fresh, human cervical cancers. Gynecol Oncol 1998, 71:308-312.

14. Sasaki Y, Shinkai T, Eguchi K, Tamura T, Ohe Y, Ohmori T, Saijo N: Prediction of the antitumor activity of new platinum analogs based on their ex vivo pharmacodynamics as determined by bioassay. Cancer Chemother Pharmacol 1991, 27:263-270.

15. Uehara T, Watanabe H, Itoh F, Inoue S, Koshida H, Nakamura M, Yamate J, Maruyama T: Nephrotoxicity of a novel antineoplastic platinum complex, nedaplatin: a comparative study with cisplatin in rats. Arch Toxicol 2005, 79:451-460.

16. Kawai Y, Taniuchi S, Okahara S, Nakamura M, Gemba M: Relationship between cisplatin or nedaplatin-induced nephrotoxicity and renal accumulation. Biol Pharm Bull 2005, 28:1385-1388.

17. Niibe Y, Tsunoda S, Jobo T, Imai M, Matsuo K, Matsunaqa K, Unno N, Hayakawa K: Phase II study of radiation therapy combined with weekly nedaplatin in locally advanced uterine cervical carcinoma (LAUCC): Kitasato Gynecologic Radiation Oncology Group (KGROG 0501)- initial analysis. Eur J Gynaecol Oncol 2008, 29(3):222-224.

18. Yokoyama Y, Takano T, Nakahara K, Shoji T, Sato H, Yamada H, Yaeqashi N, Okamura K, Kurachi H, Suqiyama T, Tanaka T, Sato A, Tase T, Mizunuma H: A phase II multicenter trial of concurrent Chemo-radiotherapy with weekly nedaplatin in advanced uterine cervical carcinoma: tohoku gynecologic cancer unit study. Oncol Rep 2008, 19:1551-1556.

doi:10.1186/1748-717X-9-55

Cite this article as: Yuan et al:: A phase II study of concurrent chemo-radiotherapy with weekly nedaplatin in advanced squamous cell carcinoma of the uterine cervix. Radiation Oncology 2014 9:55.

\section{Submit your next manuscript to BioMed Central and take full advantage of:}

- Convenient online submission

- Thorough peer review

- No space constraints or color figure charges

- Immediate publication on acceptance

- Inclusion in PubMed, CAS, Scopus and Google Scholar

- Research which is freely available for redistribution

Submit your manuscript at www.biomedcentral.com/submit
C Biomed Central 